\title{
Arctic decadal and interdecadal variability
}

\author{
Igor V. Polyakov \\ International Arctic Research Center, University of Alaska Fairbanks
}

\author{
Mark A. Johnson \\ Institute of Marine Science, University of Alaska Fairbanks
}

\begin{abstract}
Atmospheric and oceanic variability in the Arctic shows the existence of several oscillatory modes. The decadal-scale mode associated with the Arctic Oscillation (AO) and a low-frequency oscillation (LFO) with an approximate time scale of 60-80 years, dominate. Both modes were positive in the 1990s, signifying a prolonged phase of anomalously low atmospheric sea level pressure and above normal surface air temperature in the central Arctic. Consistent with an enhanced cyclonic component, the arctic anticyclone was weakened and vorticity of winds became positive. The rapid reduction of arctic ice thickness in the 1990s may be one manifestation of the intense atmosphere and ice cyclonic circulation regime due to the synchronous actions of the AO and LFO. Our results suggest that the decadal AO and multidecadal LFO drive large amplitude natural variability in the Arctic making detection of possible long-term trends induced by greenhouse gas warming most difficult.
\end{abstract}

\section{Introduction}

Arctic variability on decadal and longer timescales is the focus of this paper. There is decadal-scale variability of the atmospheric sea level pressure (SLP) over the Arctic Ocean that is likely associated with the larger scale Arctic Oscillation (AO) reflecting the strength of polar vortex [Thompson and Wallace, 1998]. This may drive the decadal variability found by Proshutinsky and Johnson [1997] in two (cyclonic and anticyclonic) wind-driven circulation regimes of the Arctic Ocean. The AO encompasses many of the features of the North Atlantic Oscillation (NAO). According to Deser [2000], the AO is nearly indistinguishable from the leading structure of variability in the North Atlantic where the NAO is a major source of low-frequency variability [Hurrell, 1995]. Figure 1 (after [Portis et al., 2000]) shows the low-frequency time series of the NAO index. There is some decadal variability as well as a mode of variability with an approximate time scale of 60-80 years. This low-frequency oscillation (LFO) is evident in various instrumental records of the Northern Hemisphere (Minobe [1997], and also [Delworth and Mann, 2000] for references therein). According to the analysis of a long-term integration of the Geophysical Fluid Dynamics Laboratory coupled atmosphere-ocean model, multidecadal sea surface temperature (SST) variability is related to fluctuations in the thermohaline circulation in the North Atlantic, particularly in SST [Delworth and Mann, 2000].

In this paper, we present evidence that the decadal-scale variability associated with the AO and interdecadal LFO were in their positive, cyclonic, phase in the 1990s. Many of the recent changes of the Arctic environment may be related to the strong positive phases of the AO and LFO during the late 1980s and 1990s. Arctic surface air temperature (SAT) for 1979-1997 shows warming [Rigor et al., 2000]. Atmospheric SLP has decreased and the cyclonic vorticity of winds has been enhanced in the late 1980s through early 1990s relative to any time in the past several decades [Walsh et al., 1996]. Using submarine-based observations of arctic ice drafts, Rothrock et al. [1999] document a substantial reduction of ice thickness in the central Arctic in the 1990s relative to the 1950-1970s.

We base our results on analysis of observational data and modeling results. The SLP data were obtained from the National Center for Atmospheric Research (1990) CD-ROM. NCEP/NCAR reanalysis daily SAT were provided by the NOAA-CIRES Climate Diagnostic Center, Boulder, Colorado. We use a coupled ice-ocean model with ice and ocean dynamics and thermodynamics. The ice dynamic model uses an elastic-plastic constitutive law. Ice 
mass and concentration are described by distribution functions. The ocean is described by a 3-D time-dependent, baroclinic, $z$-coordinate free-surface model with 29 levels. The model domain with horizontal resolution of $55.56 \mathrm{~km}$ covers the Arctic Ocean and the Greenland, Iceland, Norwegian (GIN), an Barents seas. The model was integrated from 1946 through 1997, driven by daily winds and SAT and other atmospheric parameters used in parameterized surface heat fluxes. A 5-year model spin-up with prescribed winds and SAT repeated for 1946 was used. No restoring was used during the 1946-1997 model run. Details of the problem formulation may be found in Polyakov et al. [1999].

\section{Variability of the arctic atmosphere}

Portis et al. [2000] separate the low-frequency variability of the NAO into four epochs (Figure 1). A negative epoch in the 1870-1900s followed by an extended positive epoch of 1900-1950 with a maximum about 1910-1925. A second negative period was from 1960 through about 1980 and a second positive epoch extends from 1980s at least through 1997 (for details see [Hurrell, 1995; Portis et al., 2000]).

A 52-year-long time series of NCEP/NCAR reanalysis SAT averaged over five polar regions shows that in the eastern Arctic and the Barents and GIN seas, the SAT is high in the 1950s, downtrending well into the 1960s, and followed by an upward trend in recent decades (not shown). The NCEP/NCAR SAT shows no warming trend in the late 1940s-1990s except for the Beaufort Sea. NCEP/NCAR SAT captures rapid warming during the 1979-late 1990s, also documented by Rigor et al. [2000]. This pattern of the SAT compares favorably with the LFO variability in the NAO index in late 1940s-1990s (Figure 1). The amplitude of this mode tends to decrease from the North Atlantic towards the North Pacific.

A time series of the SLP differences between locations on the British coast and Iceland $\left(65^{\circ} \mathrm{N}, 20^{\circ} \mathrm{E}\right.$ and $58^{\circ} \mathrm{N}, 2^{\circ} \mathrm{E}$, respectively) for $1946-1997$ is shown in Figure $2 \mathrm{a}$. This cross section illustrates the variability of forcing which drives warm, salty Atlantic water into the Norwegian Sea from the North Atlantic. The SLP difference time series shows fluctuations similar to what one might expect from adding decadal variability to the interdecadal LFO signal with higher values in the late 1940s-1950s and 1980-1990s (positive LFO epochs) and lower values in the 1960-1970s (negative LFO epoch). The SLP fields averaged over the positive and negative phases of the multidecadal and decadal modes of arctic variability (Figure 3) show that during negative phases of the LFO and AO, the center of high SLP in the western Arctic is well developed and the Icelandic Low is depressed while during positive phases of the LFO and AO, the SLP high in the western Arctic is weaker and the Icelandic Low is stronger extending farther into the Barents and Kara seas.

Calculated atmospheric vorticity over the central Arctic Ocean to the north of the Laptev Sea (the area within $550 \mathrm{~km}$ of $84^{\circ} \mathrm{N}, 125^{\circ} \mathrm{E}$ ) is presented in Figure 2b. This graph is an extention of the Walsh et al. [1996] time series from 1946 to 1997. The vorticity index, a characteristic of the wind cyclonicity, does not appear to have any substantial trend during the last 50 years. Rather, it seems to be modulated by both the LFO and decadal variability. In the 1960-1970s the vorticity values were generally negative and in the 1940-1950s and late 1980-1990s the vorticity values were generally positive. This pattern resembles very well, one negative, anticyclonic, and two positive, cyclonic, epochs of the LFO. The superposition of negative LFO epoch and negative AO regimes led to high anticyclonic vorticity values in mid-1960s-late 1970s, whereas superposition of positive LFO epochs and positive AO regimes led to strong cyclonicity in 1946-1952 and in late 1980s-1990s. In the early 1990s, for example, the superposition of positive LFO epoch and strongly positive AO produced a unique situation since the 1940s with extremely high positive vorticity and a prolonged cyclonic phase.

\section{Variability in the ice-ocean system}

Atmospheric vorticity serves as a measure of cyclonicity enabling us to connect atmospheric circulation with ice and ocean circulation regimes. Our modeling results show that increased 
atmospheric cyclonicity favors cyclonic ice drift in the eastern Arctic (Figure 4) and lighter ice conditions in the Eurasian Basin including the Laptev and East Siberian seas during positive, cyclonic LFO epochs (i.e. in the 1940s through early 1950s and in the 19801990s). Cyclonic winds flush multiyear ice from this area and decrease sea ice concentration resulting in numerous openings in the ice cover. For example, our model shows that in the 1990s about $40 \%$ of multiyear thick ice to the north of the Laptev Sea has been replaced by thinner ice, in qualitative corroboration with observations. Repetition of this process over several years with increased atmospheric cyclonicity results in thinner ice in the central Arctic (Figure 4).

We compared our results to published data on ice thickness variability in the central Arctic where Scientific Ice Expeditions (SCICEX) data were released [Rothrock et al., 1999] (Figure 5a). The model captures the substantial ice reduction in the 1990s over the SCICEX area (compare $1.0 \mathrm{~m}$ from the model with $1.30 \mathrm{~m}$ from observations). The difference between observed and simulated values is perhaps due to the lack of positive trend in NCEP/NCAR SAT. According to our results, the most substantial ice reduction in the 1990s occurred in the Laptev Sea and in the central Arctic. In the Beaufort Sea near the Canadian Archipelago the ice thickness increased by up to $1 \mathrm{~m}$ and more due to advection of thicker ice from the central Arctic to its periphery (Figure 4). Therefore the ice thickness averaged over the entire domain does not exhibit a quasi-linear decline like in the SCICEX area but is rather a complex superposition of decadal-scale mode of the AO and LFO and a slight downtrend. Linear approximations of the ice thickness change are shown in Figure 5 by dashed lines. A Cox and Stuart test for trends confirms the significant trend of declining ice thickness in the SCICEX area of the central Arctic but rejects this hypothesis for the entire domain (p $\leq 0.05$ ). Therefore, a linearly decreasing trend is a fair fit for the SCICEX region (Figure $5 \mathrm{~b}$ ), but is not for the entire Arctic Ocean (Figure 5a).

A climatically important link between the Arctic Ocean and the North Atlantic is the advection of arctic ice and fresh water into the adjacent seas. How does this link work under impact of the AO and LFO? Figure 6 shows computed ice and fresh water transport through Fram Strait. Observed ice volume transport (dashed line, Figure 6a) for the 1991-1997 [Vinje et al., 1998] agrees fairly well with our computations. Fluctuations of the simulated fluxes resemble the LFO pattern when increased cyclonicity in the Arctic (the 1940s-earlier 1950s and the 1990s, Figure 2b) caused an additional export of arctic ice and fresh water into the Greenland Sea. Our results also point out that in the 1990s increased atmospheric cyclonicity favored ice transport from the Arctic Ocean to the Barents Sea through the passage between the Franz Josef Land and Spitsbergen. These differences in ice and fresh water export have a pronounced impact on the thermohaline regime in the Greenland and Barents seas. The Barents Sea salinity anomalies based on 74,280 observations are shown in Figure 7 (after [Matishov et al., 1998]). Simulated salinity anomalies are also depicted in Figure 7. Both these data sets have many similarities and resemble major features of the LFO when the positive LFO epochs (the 1940s-earlier 1950s and the 1990s) correspond to a freshening and the negative LFO epoch (the 1960s) is associated with salinification in the Barents Sea. The resemblance between variability of the observed salinity (Figure 7) and the NAO index (Figure 1 ) is striking (with a correlation coefficient $\mathrm{r}=-0.55$ ), attesting to a close connection between processes in the polar regions and the North Atlantic.

\section{Conclusions}

The recent retreat of arctic ice requires an understanding of whether the ice reduction is a persistent signature of global warming due to anthropogenic impact on climate or it is a minimum of a low-frequency natural climate oscillation. Numerical models of Earth climate system [Vinnikov et al., 1999] and direct observations [Rothrock et al., 1999] show substantial ice decline in the recent decades. Vinnikov et al. suggested that the observed decrease of arctic ice extent is related to anthropogenic global warming. However, Vinje [2000] using observations over the past 135 years showed that the recent decrease in ice extent in the 
Nordic Seas is within the range of natural variability since the 18th century. A combination of century- and half-a-century-long data records and model integrations leads us to conclude that the natural low-frequency oscillation (LFO) exists and is an important contributor to the recent anomalous environmental conditions in the Arctic. This mode of oscillation is related to fluctuations in the thermohaline circulation in the North Atlantic [Delworth and Mann, 2000]. Comparison of the century-long NAO index time series and half a century time series of the polar region SAT, SLP differences, and wind vorticity index shows the existence of the LFO mode in the latter time series. There is evidence that the LFO has a strong impact on ice and ocean variability. Our results suggest that the decadal AO and multidecadal LFO drive large amplitude natural variability in the Arctic making detection of possible long-term trends induced by greenhouse gas warming most difficult.

Acknowledgments. We thank R. Colony, U. Bhatt, T. Delworth, R. Hibler, M. Ikeda, V. Kattsov, H. Kitauchi, A. Makshtas, T. Vinje, D. Walsh, and J. Walsh for useful discussions and comments. Thanks to J. Walsh for giving us the NAO index time series and to anonymous reviewers for their comments. We also thank C. Swingley for his help. This project was supported by grants from the National Science Foundation's Office Of Polar Programs (\#9806926). I.P. thanks the Frontier Research System for Global Change for financial support.

\section{References}

Delworth, T. L., and M. E. Mann, Observed and simulated multidecadal variability in the Northern Hemisphere, Climate Dynamics, submitted.

Deser, C., On the teleconnectivity of the "Arctic Oscillation", Geophys. Res. Lett., 27, 779-782, 2000.

Hurrell, J. W. Decadal trends in the North Atlantic Oscillation: Regional temperatures and precipitation, Science, 269, 676-679, 1995.

Matishov, G., A. Zyev, V. Golubev, N. Adrov, V. Slobidin, S. Levitus, I. Smolyar, Climatic Atlas of the Barents Sea 1998: Temperature, salinity, oxygen, Murmansk - Silver Spring, Russian Academy of Science and U.S. Department of Commerce, NOAA, 25 pp., 1998.

Minobe, S., A 50-70 year climatic oscillation over the North Pacific and North America, Geophys. Res. Lett., 24, 683-686, 1997.

Polyakov, I. V., A. Yu., Proshutinsky, and M. A. Johnson, Seasonal cycles in two regimes of Arctic climate, J. Geophys. Res., 104, 25761-25788, 1999.

Portis, D. H., J. E. Walsh, M. El Hamly, P. J. Lamb, Seasonality of the North Atlantic Oscillation, J. Climate, 2000, submitted.

Proshutinsky, A. Yu., and M. A. Johnson, Two circulation regimes of the wind-driven Arctic Ocean, J. Geophys. Res., 102, 12493-12514, 1997.

Rigor, I. G., R. L. Colony, and S. Martin, Variations in surface air temperature observations in the Arctic, 1979-97, J. Climate, 13, 896-914, 2000.

Rothrock, D. A., Y. Yu, and G. A. Maykut, Thinning of the arctic sea-ice cover, Geophys. Res. Lett., 26, 3469-3472, 1999.

Thompson, D. W. J., and J. M. Wallace, The Arctic Oscillation signature in the wintertime geopotential height and temperature fields, Geophys. Res. Lett., 25, 1297-1300, 1998.

Vinje, T., Anomalies and trends of sea ice extent and atmospheric circulation in the Nordic Seas during the period 1864-1998, J. Climate, 2000, to appear.

Vinje, T., N. Nordlund, and A. Kvambekk, Monitoring ice thickness in Fram Strait, J. Geophys. Res., 103, 10437-10449, 1998

Vinnikov, K. Y., A. Robock, R. J. Stouffer, J. E. Walsh, C. L. Parkinson, D. J. Cavalieri, J. F. B. Mitchell, D. Garrett, and V. F. Zakharov, Global warming and Northern Hemisphere sea ice extent, Science, 286, 1934-1937, 1999.

Walsh, J. E., W. L. Chapman, and T. L. Shy, Recent decrease of sea level pressure in the central Arctic, J. Climate, 9, 480-486, 1996.

I. Polyakov, International Arctic Research Center, University of Alaska Fairbanks, Fairbanks, AK 99775 (e-mail: igor@iarc.uaf.edu)

M. Johnson, Institute of Marine Science, University of Alaska Fairbanks, Fairbanks, AK 99775 (e-mail: johnson@ims.uaf.edu)

(Received June 19, 2000; revised September 19, 2000; accepted October 4, 2000) 
Figure 1

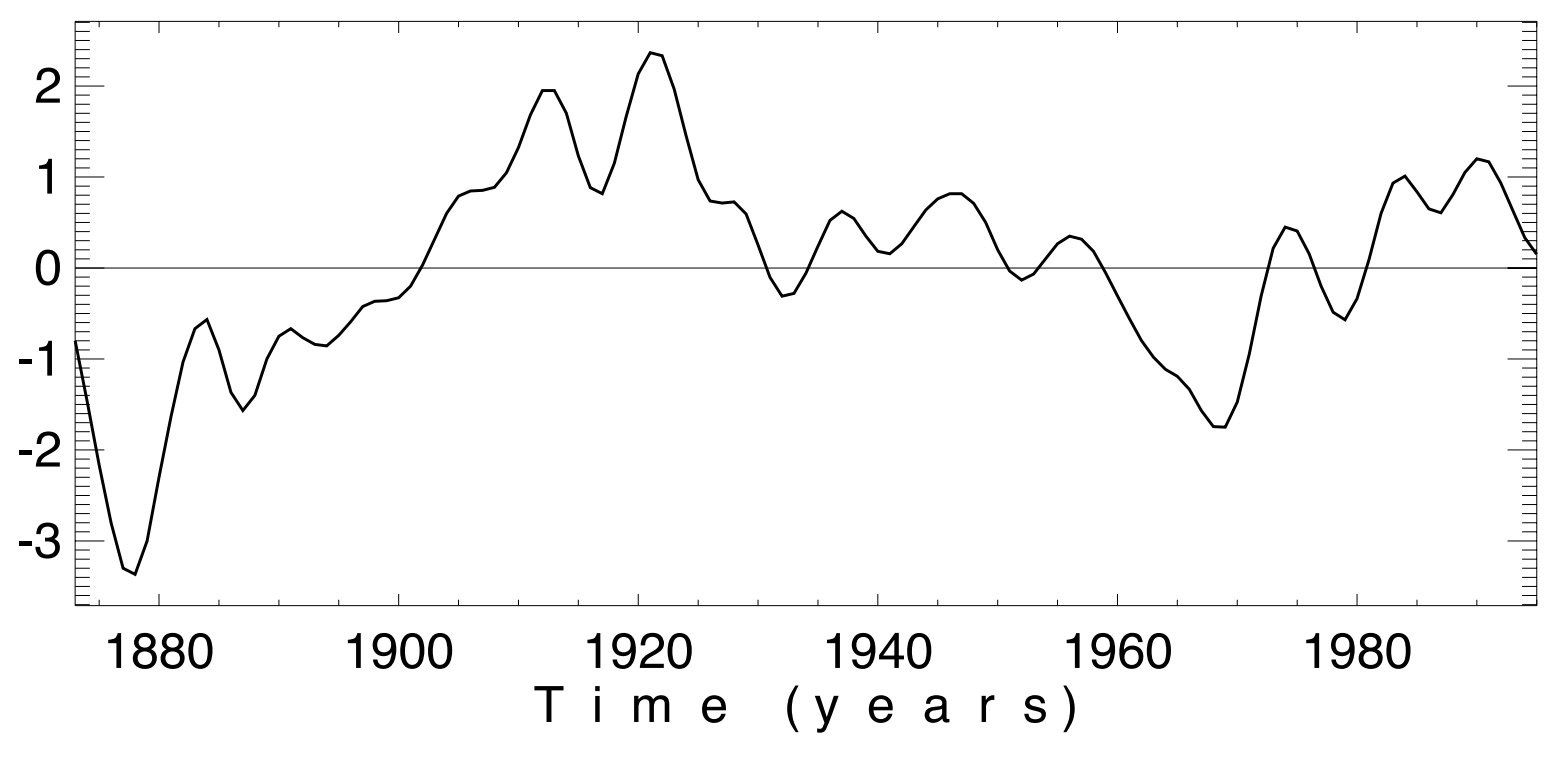


Figure 2
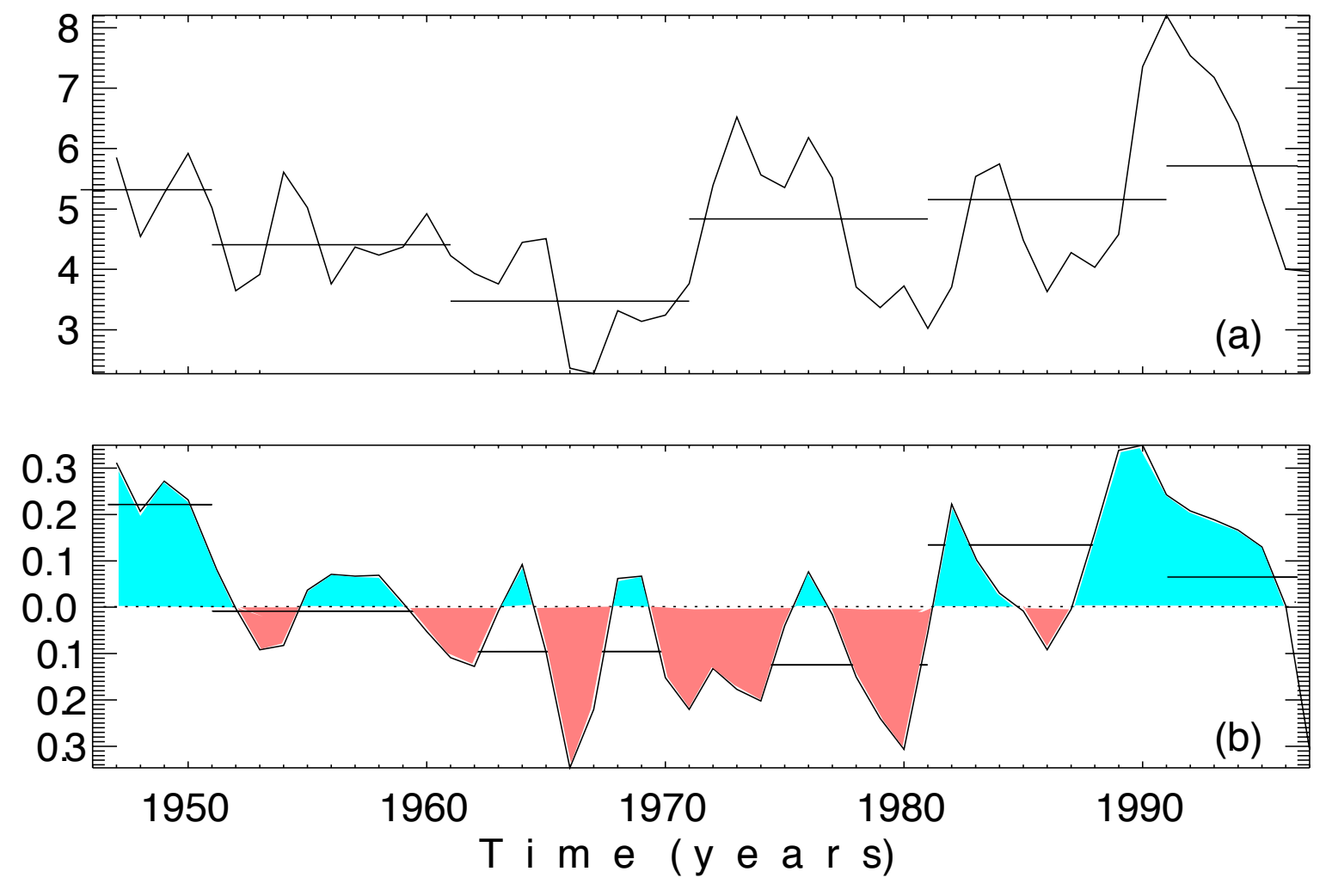


\section{Figure 3}

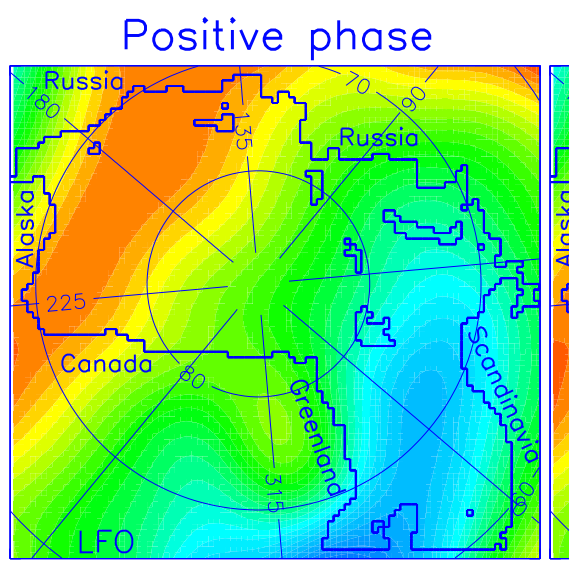

Negative phase
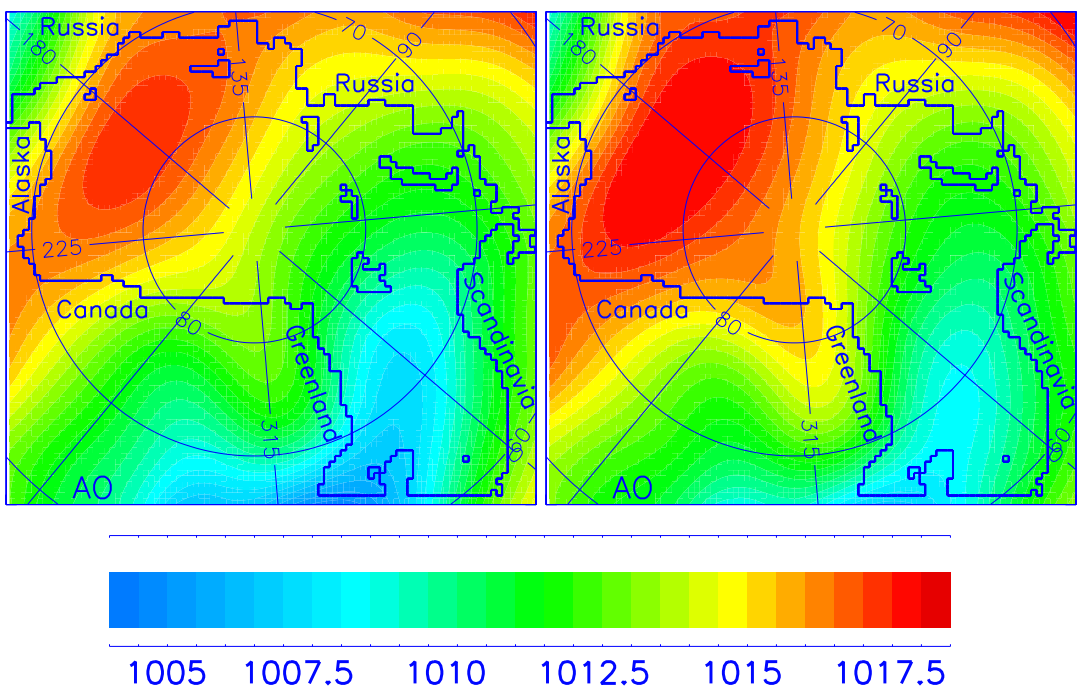
Figure 4

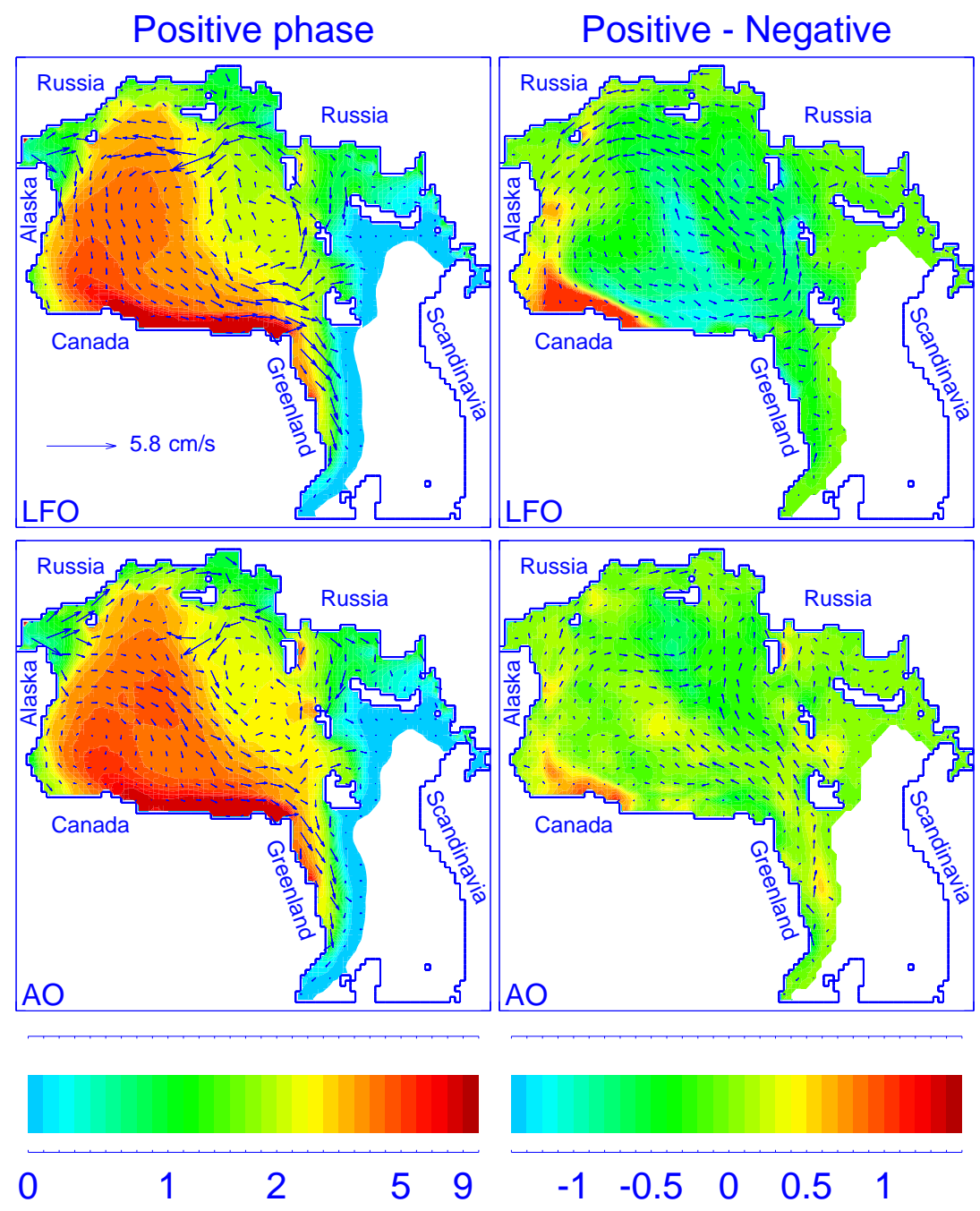


Figure 5
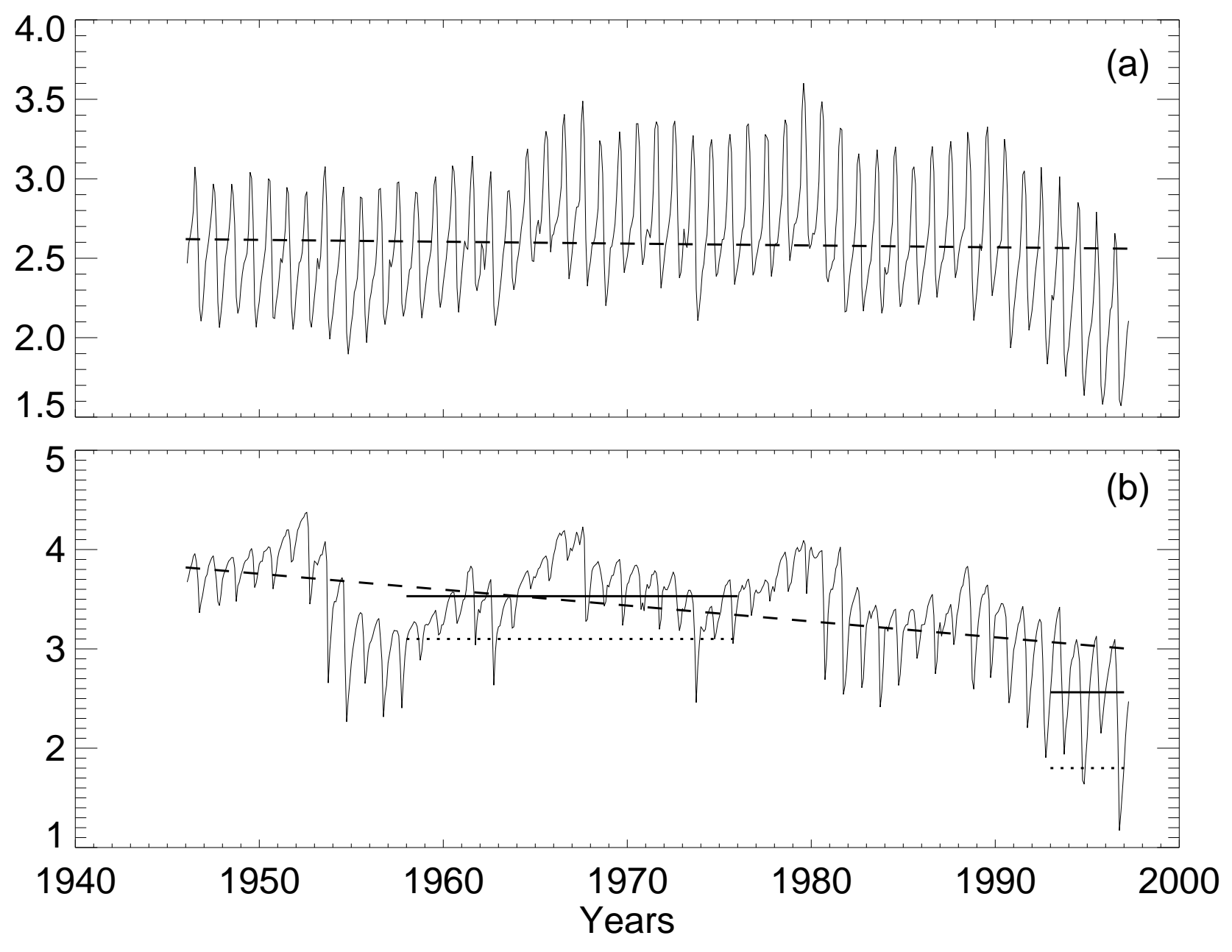
Figure 6
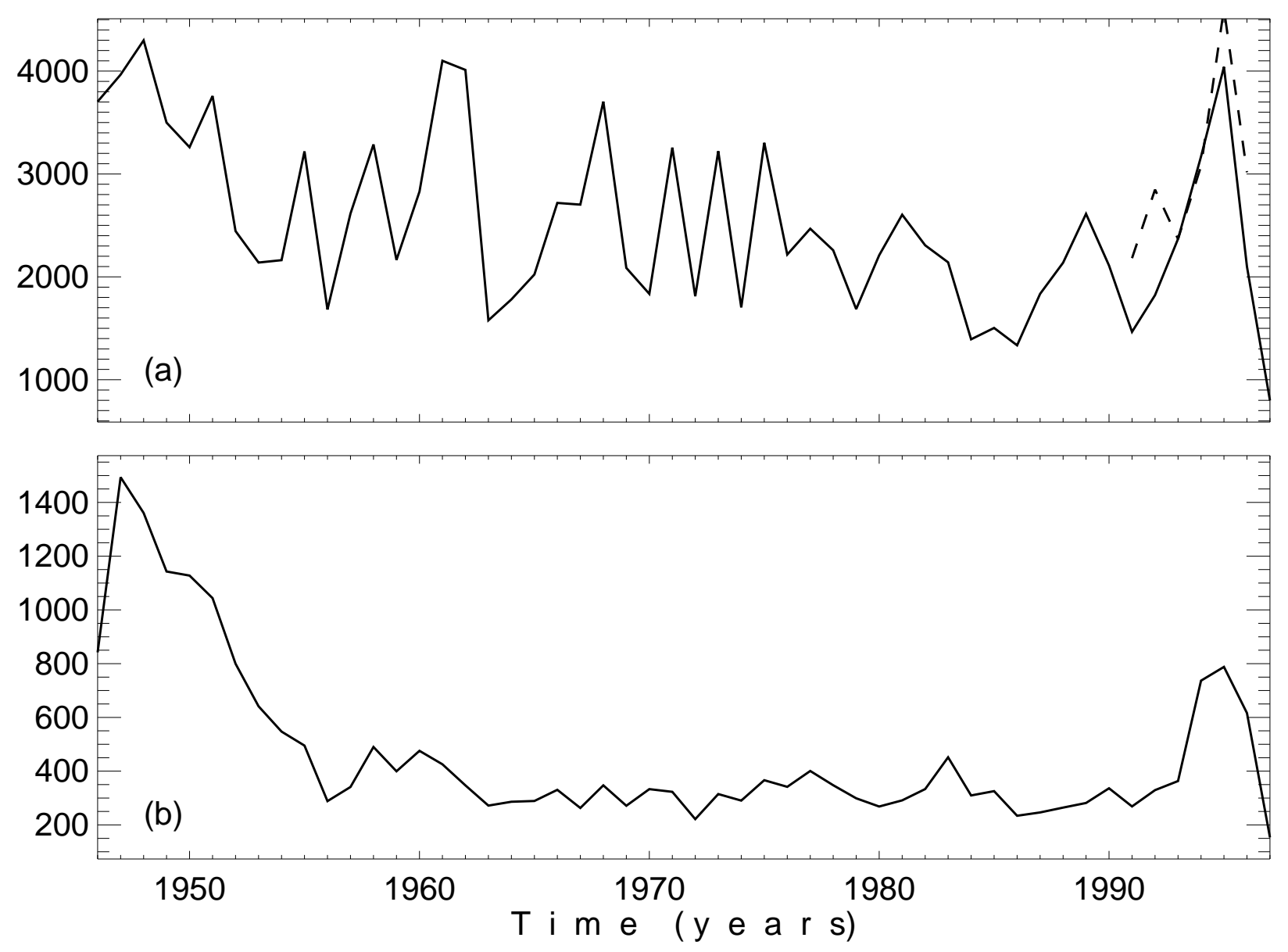
Figure 7

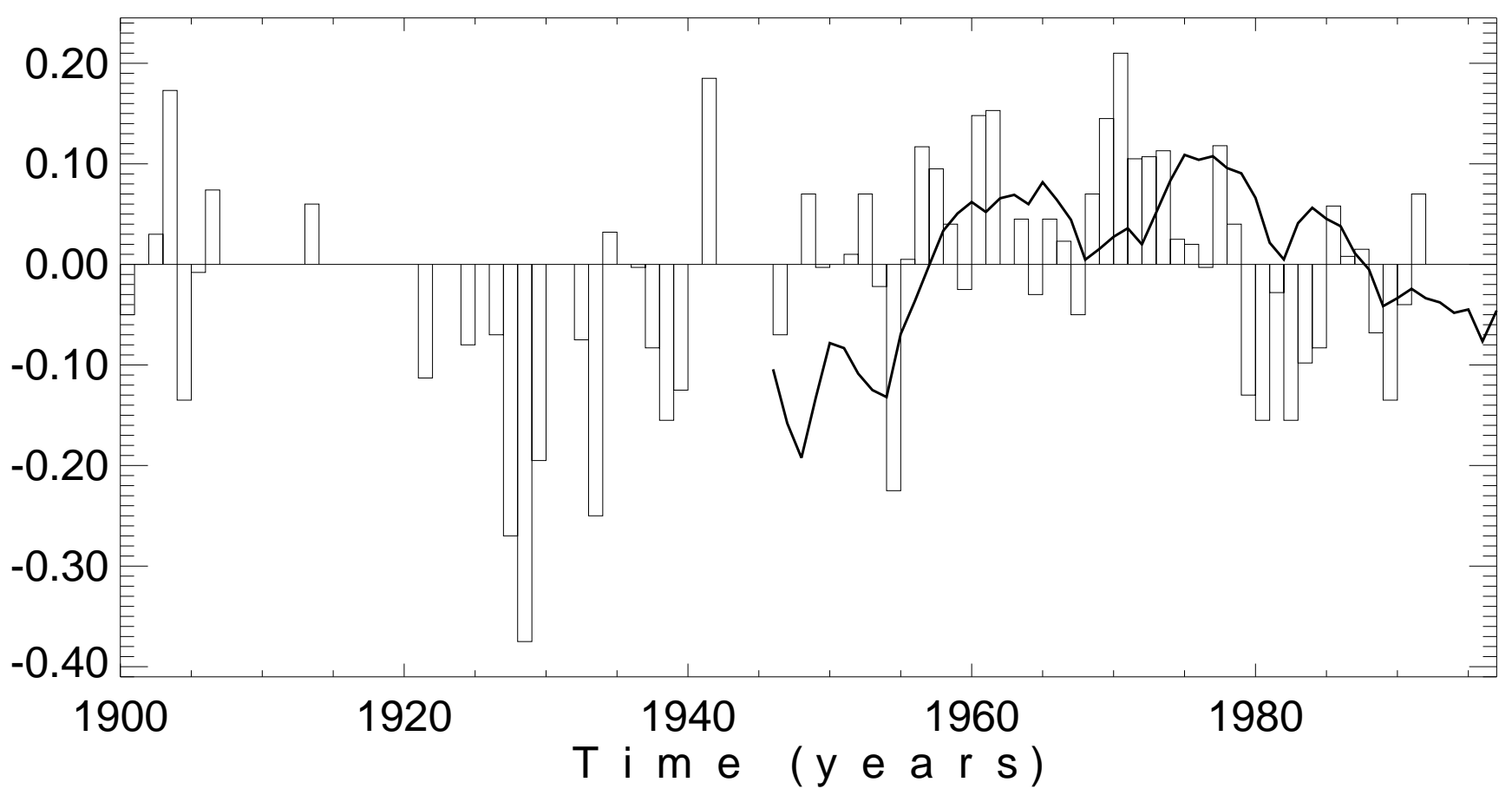

